\title{
ТЕОРЕТИЧЕСКИЕ АСПЕКТЫ УПРАВЛЕНИЯ ИННОВАЦИОННЫМ РАЗВИТИЕМ ОТРАСЛЕЙ БИОЭКОНОМИКИ
}

\author{
(c) 2021 Руденко Иван Романович \\ младший научный сотрудник кафедры экономики, управления и аудита \\ Юго-Западный государственный университет, Россия, Курск \\ E-mail: Rudenko-Ivan.R@yandex.ru
}

В данном исследовании рассмотрены теоретические аспекты управления инновационным развитием отраслей биоэкономики. На современном этапе инновационное развитие отраслей биоэкономики является важной составляющей при переходе от экономики с сырьевой направленностью к экономике инновационного типа. В качестве предпосылок формирования биоэкономики можно отметить увеличение объемов использования возобновляемых источников сырья, внедрение новых методов глубокой переработки и биологизацию среды жизнедеятельности человека.

Ключевые слова: биоэкономика, инновации, биотехнологии, система управления, инновационный процесс.

Введение. Согласно экспертным данным Технологической платформы БиоТех-2030 по ряду направлений рынок биотехнологий ежегодно увеличивается на 5-30\% и к 2025 году может достичь 2 трлн. долл., при этом доля России в общемировом объеме практически равна нулю [16].

По прогнозу Организации экономического сотрудничества и развития до 2030 года значительно возрастет доля биологизации таких направлений как химическая и фармакологическая промышленности, сельскохозяйственное производство (рис. 1).

В нашей стране сосредоточены колоссальные запасы природных ресурсов, что позволяет поддерживать текущий уровень развития биоэкономики, кроме того в России сформирован значительный потенциал биотехнологий, но действенные механизмы управления и формирования экономических отношений в рамках инновационного развития отраслей биоэкономики практически отсутствуют, в связи с чем возникает риск потери рынков сбыта для биотехнологической продукции и возможности конкурировать с импортными производителями. Данная тенденция обуславливает необходимость инновационного развития биоэкономики России и ставит задачу совершенствования подходов управления.

Литературный обзор. Обеспечение инновационного развития отраслей биоэкономики с минимальными затратами на биологизацию традиционных направлений жизнедеятельности должно основываться на управленческих решениях направленных на сохранение и совершенствование данного инновационного развития [13].

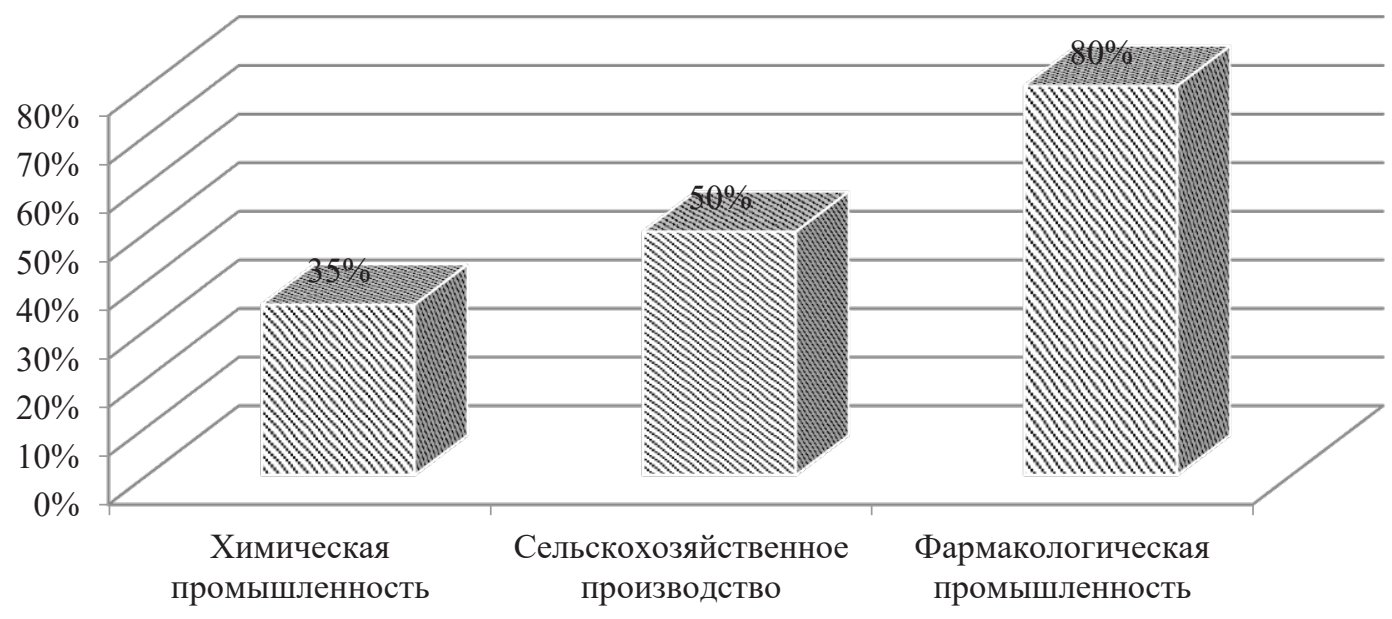

Рисунок 1. Прогноз биологизации ряда отраслей к 2030 году 
Управление инновационным развитием предполагает комплекс мер, на основе принципов и подходов к принятию решений, учитывающих критерии эффективности таких решений [3]. Ю.О.Бакланова делает акцент на том, что управление инновационным развитием должно учитывать открытость и гибкую адаптивность к динамично изменяющимся условиям среды [1].

А. Уайскофа считает, что открытость либо создает условия для преобразования к лучшему, которое может выражаться в росте конкуренции на рынке биотехнологий, или к худшему, создав риск вмешательства в бизнес-процессы, что негативно отразится на отрасли [22]. По данным ОЭСР открытость инновационной деятельности напрямую связана с ее достижимостью и доступностью.

Материалы и методы. Основой исследования послужили труды в области проблем управления инновациями и изучение опыта развития биоэкономики зарубежом.

Результаты. В странах с высоким уровнем биологизации инициатором стимулирования биоэкономики является государство, путем принятия мер административного и экономического воздействия (табл. 1), поэтому биоэкономика относится к ряду научно-практических приоритетов [2].

Наибольшее развитие в части потребления и производства биотехнологических продуктов достигли Япония, ЕС, США, Корея, Канада, кроме того, за последние десять лет в гонку инновационного развития биоэкономики вошли Китай, Индия и Бразилия, они реализуют масштабные программы развития биотехнологий и модернизируют действующие традиционные производства.

Масштабная модернизация производств и стимулирование развития биоэкономики в зарубежных странах происходит путем прямого финансирования биотехнологий, так как накопленный ресурсный потенциал в виде компетенций, технологий, технопарков и иных элементов невозможно реализовать без прямого участия государства, о чем свидетельствует несколько замороженных проектов в области биотехнологий в России [14].

Процесс управления биоэкономикой необходимо строить, основываясь на постановке цели и согласовании ее с основными силами региона; разработке стратегии развития биоэкономики в регионе с привлечением внешних экспертов и осуществлении контроля ее реализации.

Благоприятные условия для инновационного развития отраслей биоэкономики реализуются через эффективную систему управления, позволяющую инициаторам взаимодействовать с консультантами, фондами, инвесторами и другими участниками процесса.

Модель системы управления биоэкономикой в основном базируется на традиционных подходах и отражает систему институтов и формирование инфраструктуры, в обеспечении интеграции науки и промышленности. Процесс выстраивается от постановки цели до контроля за реализацией, с запуском инновационного процесса, результатом которого является реализация биотехнологий (рис. 2).

Взаимодействующие между собой участники в процессе создания и использования инноваций формируют инновационную систему, заложенную в инновационную политику.

Эффективность инновационной политики и предполагаемый прогресс зависят от подходов к взаимодействию всех участников, что и определяет необходимость совершенствования управленческих инструментов применяемых в процессе и формирование стратегии развития биоэкономики.

Таблица 1. Меры стимулирования биоэкономики в зарубежных странах

\begin{tabular}{|l|l|}
\hline Государство & Меры стимулирования \\
\hline США & $\begin{array}{l}\text { Прямое государственное финансирование биотехнологических предприятий через } \\
\text { специальный фонд National Institutes of Health - крупнейший субъект, осуществляющй } \\
\text { финансирование биотехнологических исследований в США. }\end{array}$ \\
\hline ЕС & Развитие биотехнологий посредством венчурного финансирования. \\
\hline Китай & Стимулирующие меры государства в трудовом, налоговом и финансовом регулировании. \\
\hline Бразилия & $\begin{array}{l}\text { Прямое государственное финансирование биотехнологий через специальный фонд } \\
\text { Віотесhnоlogу Sectoral Fund. } \\
\text { Предоставление грантов исследовательским проектам в области биотехнологий через } \\
\text { Бразильское «Агентство инноваций». }\end{array}$ \\
\hline Индия & $\begin{array}{l}\text { Прямое государственное финансирование малого предпринимательства в сфере биотех- } \\
\text { нологий. }\end{array}$ \\
\hline
\end{tabular}




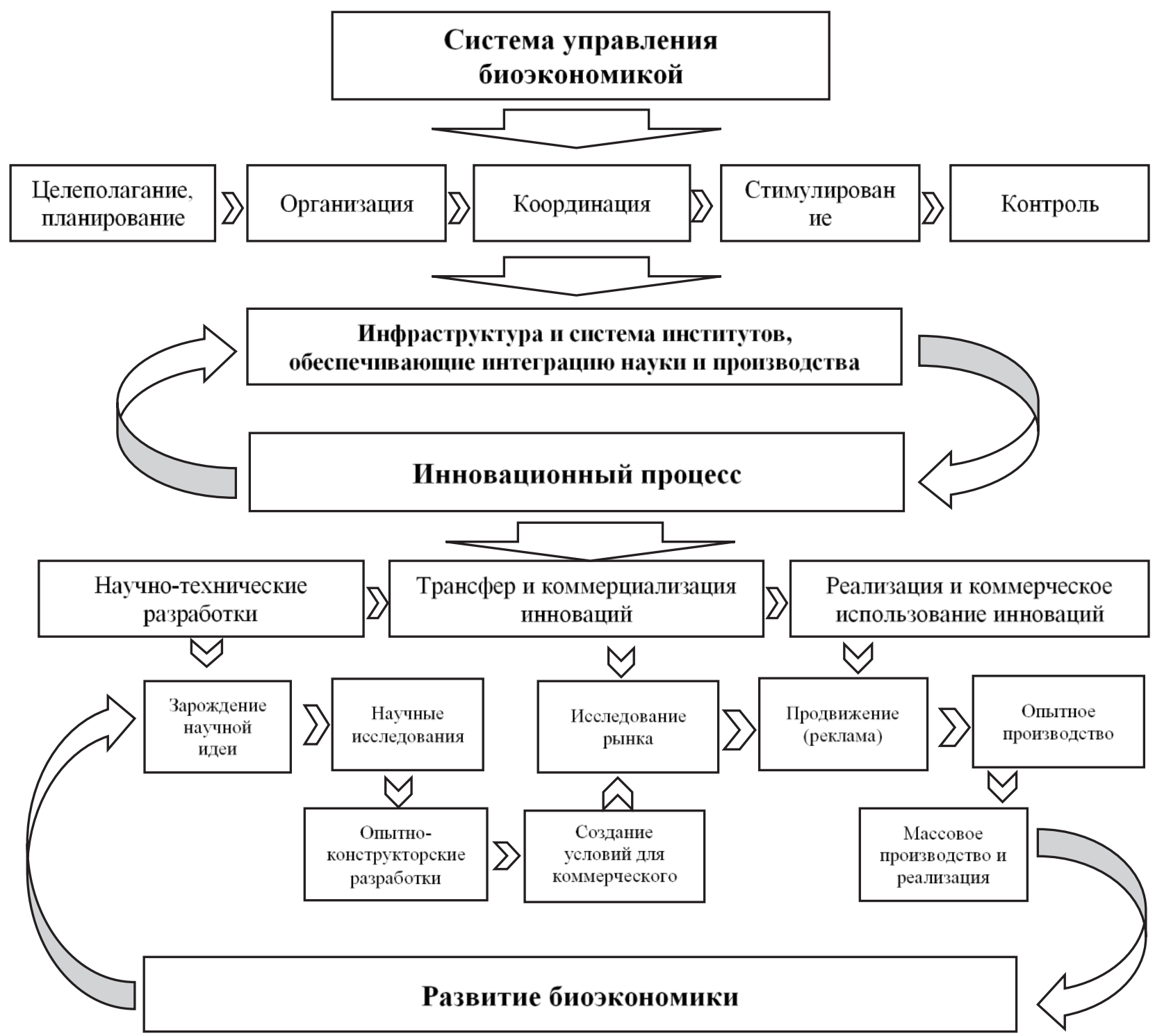

Рисунок 2. Модель системы управления инновационным развитием биоэкономики

Российскими и зарубежными учеными предложено множество подходов к решению проблемы стратегического развития [19].

Ряд ученых полагает, что для России будет приемлема стратегия догоняющей модернизации [12], другие полагают, что стоит использовать смешанную стратегию инновационного развития, так как в данном случае расширяются возможности практической деятельности и использования собственных инноваций [5].

На наш взгляд смешанная стратегия в инновационном развитии отраслей биоэкономики является более приемлемой для России, так как необходимо учитывать многоукладность технологического потенциала, дифференциацию уровней развития территорий и их инновационные возможности.

Обсуждение. Использование биоресурсов от растений и насекомых до молекул в промышленных целях строится на основном принципе биоэкономики - биологизации [13]. Инновационное развитие отраслей биоэкономики в значительной степени определяется внедрением биотехнологий в традиционные сектора экономики и росте интереса к коммерциализации исследований и моделированию биологических систем $[9,11,20]$. Значимость биотехнологий в современном мире определяется и тем, что интерес к ним находится на одном уровне с нано и информационными технологиями [10, 21]. Био- 
технологии являются движущей силой множества отраслей промышленности, АПК, сельского хозяйства, нефтепереработки, утилизации отходов и других отраслей, формирующих инновационное развитие биоэкономики $[15,17]$. Биотехнологии позволяют заменить устоявшиеся традиционные технологии, и относятся к «подрывным» технологиям, приносят совершенно новые продукты и услуги, постепенно вытесняя поддерживающие инновации с последующим кардинальным изменением всей инновационной системы [18].

На наш взгляд, инновационное развитие отраслей биоэкономики предполагает эффективную систему экономических отношений, по использованию и наращиванию инновационного потенциала территории, готовую к трансформации под новые тенденции, задаваемые рынком.

В целом биоэкономику чаще всего опреде- ляют как знаниеемкую эксплуатацию биологических ресурсов, биологических процессов и принципов для стабильного производства товаров и услуг во всех секторах экономики [4]. Стоит отметить, что биоэкономическая проблематика является одним из перспективных направлений развития как на региональном, государственном так и на международном уровнях [7].

Выводы. Управление инновационным развитием отраслей биоэкономики должно основываться на внедрении биотехнологий в традиционные отрасли, что позволит решить широкий спектр социальных, экологических и экономических проблем, создать конкурентоспособную среду способную заявлять себя на мировом рынке, обеспечить независимость государства в высокотехнологичном секторе, а также укрепить межгосударственные связи.

\section{Библиографический список}

1. Бакланова Ю.О. Управление инновационным потенциалом в регионах России / Ю. О. Бакланова // Региональная экономика: теория и практика. - 2008. - № 19. - С. 94-97.

2. Беляков С.А. Механизм стимулирования развития биотехнологий в зарубежных странах / С. А. Беляков // Сибирский журнал науки и технологий. - 2009. - № 4. - С. 214-218.

3. Горбов Н.М. Регулирование инновационной деятельности на основе управления инновационным потенциалом / Н. М. Горбов, И. В. Татаринцева // Вестник БГУ. - 2013. - № 3. - С. 99-102.

4. Гордеева И.В. Биоэкономика как одно из стратегических направлений устойчивого развития / И. В. Гордеева // Научное обозрение. Экономические науки. - 2019. - № 1. - С. 16-21.

5. Гусаков М.А. Тенденции характеристик научно-инновационного процесса в макрорегионах России / М.А. Гусаков // Инновации. - 2017. - № 6(224). - С. 38-44.

6. Зелёная экономика и цели устойчивого развития для России: коллективная монография / С.Н.Бобылев, С.М.Михайлова, П.А. Кирюшин [и др.]. - М.: Федеральное государственное бюджетное образовательное учреждение высшего образования «Московский государственный университет им. М. В. Ломоносова» (экономический факультет), 2019. - 284 с.

7. Коровникова Н.А. Биоэкономика: инициативы, перспективы, особенности / Н.А. Коровникова // Социальные и гуманитарные науки: Отечественная и зарубежная литература. Сер. 2, Экономика: Реферативный журнал. - 2019. - № 1. - С. 15-20.

8. Кружалин В.И. Основные аспекты инновационного развития экономики региона / В. И. Кружалин, М. А. Морозова, В.С.Кудряшов // Наука и образование: сохраняя прошлое, создаём будущее: сборник статей XVIII Международной научно-практической конференции, Пенза, 05 ноября 2018 года. - Пенза: «Наука и Просвещение» (ИП Гуляев Г.Ю.), 2018. - С. 105-107.

9. Кудрявцева О.В. Биотехнологические отрасли в России и в мире: типология и развитие / О.В. Кудрявцева, Е. Ю. Яковлева // Современные технологии управления. - 2014. - № 7(43). - С. 32-37.

10. Македон Г.М. Биоэкономика как одна из основ устойчивого развития общества / Г. М.Македон, Н.П.Талавыря // Известия Великолукской государственной сельскохозяйственной академии. - 2013. - № 1 . - С. 31-35.

11. Мурзагарина 3.Е. Современные концепции истины. Философия познания в новых отраслях: биотехнология / 3.Е. Мурзагарина // Наука, образование и культура. - 2019. - № 8 (42). - С. 33-35.

12. Полтерович $B$. Федеральное агентство развития: оно необходимо для разработки и реализации успешных стратегий / В. Полтерович // Проблемы теории и практики управления. - 2018. - № 3. - С. 35-41. 
13. Пястолов С. М. Какая инновационная политика нужна биоэкономике? / С. М. Пястолов // Социальные и гуманитарные науки. Отечественная и зарубежная литература. Сер. 8, Науковедение: Реферативный журнал. - 2019. - № 1. - С.112-116.

14. Пястолов С. М. Организационные структуры биоэкономики / С. М. Пястолов // Социальные и гуманитарные науки. Отечественная и зарубежная литература. Сер. 8, Науковедение: Реферативный журнал. - 2019. № 2. - С.135-141.

15. Сидоров А.А. Выдающие результаты деятельности лидеров мировой биоэкономики / А. А. Сидоров // Региональное развитие. - 2016. - № 1. - С.10-18.

16. Стратегическая программа исследований Технологической платформы БиоТех2030. - Утверждена Решением Правления НТ НП «ТП БиоТех2030» 07.03.2014 г.

17. Тронина И.А. Особенности управления инновационным развитием российских предприятий в сфере переработки отходов: эколого-экономический аспект / И.А.Тронина, Е.Е. Кононова, О.В.Магомедалиева, И. В. Мусатова // Вестник ОрелГИЭТ. - 2018. - № 4(46). - С. 170-174.

18. Шевченко Н.Н. Понятие подрывных инноваций и предпосылки их возникновения в компании / Н. Н. Шевченко, С.М.Скрябина, О.В.Калинина // Неделя науки СПбПУ: Материалы научной конференции с международным участием. Институт промышленного менеджмента, экономики и торговли, Санкт-Петербург, 19-24 ноября 2018 года. - Санкт-Петербург: Федеральное государственное автономное образовательное учреждение высшего образования «Санкт-Петербургский политехнический университет Петра Великого», 2018. - С. 241-243.

19. Шинкевич А.И. Организационно-экономические аспекты функционирования инжиниринговых центров в инновационной экономике / А.И.Шинкевич, Ю.А. Абуталипова // Вестник Белгородского университета кооперации, экономики и права. - 2017. - № 6(67). - С. 60-69.

20. Экономические основы экологии: учебник / В.В.Глухов, Т.В.Лисочкина, Т.П.Некрасова; С.-Петерб. гос. техн. ун-т. Фак. экономики и менеджмента. 2-е изд., перераб. и доп. - СПб.: Спец. Лит., 1997. - 304 с.

21. Эрк А.Ф. Анализ предпосылок развития биоэкономики в сельском хозяйстве / А.Ф.Эрк, Е.В.Тимофеев, Л. Ю. Смирнова, И.А. Субботин, В.А.Размук, Т. Ранта-Корхонен // Технологии и технические средства механизированного производства продукции растениеводства и животноводства. - 2019. - № 3 (100). - С.203211.

22. Wyckoff A. The Economic and Social Impact of Electronic Commerce (Organisation for Economic Co-Operation and Development (OECD), 1999), p. 11. 